\title{
Labetalol in Comparison to Methyl Dopa in Treatment of Gestational Hyperten- sion, A Randomized Trial
}

\author{
Mahmoud Alalfy ${ }^{{ }^{1}}$, E.Eltaieb ${ }^{2}$ and Mahmoud.Soliman ${ }^{3}$
}

${ }^{1}$ Assistant Researcher, Reproductive Health and Family Planning Department, National Research Centre, Egypt, Specialist of Obstetrics and Gynecology at Aljazeerah Hospital, Egypt

${ }^{2}$ Lecturer in Obstetrics and Gynecology, Ain Shams University, Egypt

${ }^{3}$ Lecturer, Obstetrics and Gynecology Department, Kasralainy Faculty of Medicine, Cairo University, Egypt

${ }^{*}$ Corresponding author: Mahmoud Alalfy, Assistant Researcher, Department of Reproductive Health and Family Planning, National research Centre, Egypt, Tel: +2 1002611058, E-mail: mahmoudalalfy@ymail.com

Citation: Mahmoud Alalfy, E.Eltaieb, Mahmoud.Soliman (2018) Labetalol in Comparison to Methyl

Dopa in Treatment of Gestational Hypertension, A Randomized Trial. J Gynecol Res 4(1): 101. doi:

10.15744/2454-3284.4.101

Received Date: January 25, 2018 Accepted Date: April 09, 2018 Published Date: April 11, 2018

\begin{abstract}
Objective: To evaluate the value and safety of labetalol in comparison to Alfa methyldopa in treatment of pregnant women with pregnancy-induced hypertension (PIH).

Methods: 264 patients with PIH were randomly distributed to take either methyldopa (group 1) labetalol (group 2). or Intake of medications with respect to Age, gravidity, Blood Pressure measurement, albumin in urine measurement Levels, Side Effects, dose of the drug, increasing duration of pregnancy, mode of delivery, Perinatal safety and APGAR scores were studied. The statistical level of significance was taken at $\mathrm{P}<0.05$.

Results: A labetalol is very effective in controlling blood pressure and has earlier onset of action than methyldopa. Labetalol is very efficient in managing blood pressure, avoiding preeclampsia and eclampsia with statistically significant values in reducing Blood pressure in comparison to methyldopa with s $\mathrm{P}$ value less than 0.05 and increasing the length of pregnancy to reach fetal maturity. Labetalol has lower side effects than methyldopa. There is no difference in the 2 drugs as regard obstetric interference. Both drugs are safe for the neonate.

Conclusion: Labetalol is more safe, has lesser side effects on the mother and the neonate has a more rapid action in obtaining enough control of pressure with significant lengthening of the period of pregnancy if it is used in treatment of pregnancy complicated with hypertension.
\end{abstract}

Keywords: Labetalol; Methyldopa; Pregnancy; Preeclampsia; Hypertension

List of abbreviations: PE: Preeclampsia; PIH: Pregnancy Induced Hypertension; BP: Blood Pressure; GCP: Good Clinical Practice

\section{Introduction}

Hypertension is the most frequent disorder that happens in gestation [1]. Hypertensive problems comprise around ten percent of pregnancy and are one of the chief factors that can cause death to mothers and fetuses [2].

Hypertension is associated with an increase in the possibility of complications to mother, fetus and neonate as preterm delivery, chronic hypertension, intrauterine fetal growth retardation, perinatal death, acute renal failure, antepartum hemorrhage, postpartum bleeding and death of the mother [3-7].

Determining of the risk of developing hypertension in pregnancy can make control of elevated blood pressure more successful and effective. During this time the maternal and fetal state are followed with adjustment of hypertension by antihypertensive medications. The chance of having severe degree of hypertension is diminished to the half by taking antihypertensive agents [8].

A wide range of antihypertensive drugs are the reason of success of management of pregnancy induced hypertension [9-11].

Methyldopa was used on a large scale for management of hypertension during gestation due to its efficiency and safety for fetuses and pregnant ladies as an antihypertensive therapy with a drawback that it takes longer duration to work and also less effective as a hypotensive agent. However, it is still the most commonly utilized therapy for long term management of blood pressure during pregnancy. Methyldopa has a central action with its adrenergic antagonistic effect that causes activation of central alpha 2 receptors that leads to diminishing in sympathetic nerve stimulation causing arterial vasodilatation and so a decrease in Blood 
Pressure. There are no available data that indicate any hazardous effect on the off springs in the Methyldopa treated patients. When methyldopa is given in high doses, the sedative and depressant effects of methyldopa are noted. Methyldopa should not be used if there is a risk of maternal depression where a beta-blocking drug or calcium channel blocker can be more appropriate. Labetalol has a better treating efficiency in controlling blood pressure when compared to other anti-hypertensive drugs [12].

Labetalol is a mixed alpha and beta-blocking medication and has the advantage over other beta blockers as it has an extra arteriolar vasodilating effect that helps to decrease peripheral vascular resistance with a slight or no decrease in cardiac output.

Advantage of labetalol is its availability in an injectable and oral form and the time to start its action is earlier than methyldopa [12].

However now, it is known that b-blockers cross the placental barrier and may cause a decrease in fetal heart rate.

Experimental evidence also suggests that $\beta$-blocking drugs decrease fetal affordability to hypoxic stress [12].

\section{Patients and Methods}

\section{Study design}

A Double blinded randomized controlled trial superiority with allocation ratio 1:1.

\section{Study Settings}

was carried out in multicentres at Ain Shams University maternity hospital in collaboration with kasralainy maternity hospital and National research centre, Egypt and Aljazeerah hospital, Egypt.

\section{Study duration}

The study was conducted in the period from 5 January 2017 till 10 december 2017.

\section{Eligibility criteria}

Inclusion and exclusion criteria.

\section{Inclusion criteria:}

1. Pregnant women aged 22-40 years.

2. Gestational age between 24 and 34 weeks.

3. Blood pressure greater than or equal to $140 \mathrm{~mm} \mathrm{Hg}$ systolic or greater than or equal to $90 \mathrm{~mm} \mathrm{Hg}$ diastolic or more after blood pressure measurement on 2 occasions with 4 hours apart in a previously normal blood pressure.

4. Patients were kept in house with regular follow up visits.

\section{Exclusion Criteria:}

1. Pregnant women with underlying chronic hypertension, history of antihypertensive medication before 20 week gestation and secondary hypertension.

2. Patients with molar pregnancies, multiple pregnancy, placenta previa.

3. Pregnant women with renal disease, hematological disease, heart disease.

\section{Intervention}

Randomized in to 2 groups. Group A will receive labetalol and group B will receive alpha methyldopa then measure BP.

\section{Subjects}

Study group: 264 women attending Ain Shams University maternity hospital. Patients were distributed in two groups randomly. After randomization group A received labetalol $100 \mathrm{mg}$ tid and group B received methyldopa $250 \mathrm{mg}$ tid as starting dose. Mean Arterial pressure (MAP) was calculated.

Patients were kept in house and they were asked to come for regular follow up in the antenatal clinic in a fixed visits where Patients were monitored in the antenatal clinic after $48 \mathrm{hrs}$ from taking the drug and dose was assessed to control BP When there was no fall in BP even after 48 hours of drug therapy, dose of the drug was doubled. Then monitored in the antenatal clinic weekly for two weeks. Then every 2 weeks till delivery.

\section{Measurement of BP}

Auscultatory measurement with the sphygmomanometer is the most widespread method for indirect BP determination, having a high concordance level with the direct intra-arterial method. 
Guidelines include:

- Seat the woman for 5-10 minutes prior to BP measurement. In semi sitting or left lateral position.

- Cuff size adequate to the patient's arm circumference and positioned $2-3 \mathrm{~cm}$ above the antecubital fossa.

- Positioning of the central portion of the rubber bladder on the brachial artery.

- Positioning of the upper limb at the heart level.

\section{Outcomes}

Primary outcome: Control of mean arterial BP in mmHg in women with pregnancy induced hypertensions within 6 months.

$\checkmark$ Secondary outcome:

- Need for adding antihypertensive drugs.

- Side effect of drug used:

$\triangleright$ Side effect of labetalol:

- More common: nausea.

- Less common.

$\triangleright$ Blurred vision or other changes in vision.

$>$ Confusion.

$\triangleright$ Dizziness, fainting, light headache when getting up from lying or sitting position.

$\triangleright$ Side effect of alpha methyldopa:

- More common :drowsiness, dryness of mouth, headache.

- Less common: fever shortly after taking the drug.

\section{Observations}

1. Fall in mean arterial BP with labetalol/methyldopa.

2. Time required controlling BP.

3. Average dose of drugs required to control BP.

4. Side effects of drugs.

\section{Methods}

Randomization: Randomization of cases was done by computer method. 264 women with pregnancy induced hypertension were enrolled in the study and were distributed in two groups:group A and group B. The randomization allocation was 1:1.The two groups are randomly selected.

Allocation and Concealment: 264 opaque envelopes were numbered serially and in each envelope the corresponding letter which donate the allocated group was put according to randomization table then all envelops were closed and put in one box. When the first patient arrives the first envelope was opened and the women were allocated according to the letter inside.

\section{Blinding}

1. Subjects

2. Investigator

3. Outcome assessor

4. Caregiver

\section{Sample size: Sample Size Calculation}

The required sample size has been calculated using the $\mathrm{G}^{\star}$ Power Software (Universität Düsseldorf, Germany).

The primary outcome measure is the proportion of patients with adequate control of blood pressure at 48 hours from starting treatment, defined as systolic blood pressure $<140 \mathrm{mmHg}$ and diastolic blood pressure $<90 \mathrm{mmHg}$. The secondary outcome measure is the proportion of patients that would undergo spontaneous onset of labor.

There is at present no adequate information regarding the expected difference in the outcome measures between labetalol and methyldopa in patients with gestational hypertension. So, the present study tries to target an effective size that would be clinically relevant.

The study was conducted after approval of the ethical committee of Ain Shams University Maternity Hospital. Patients signed an informed consent to participate in the study. 
Results

\begin{tabular}{|c|c|c|c|c|c|}
\hline & \multicolumn{2}{|c|}{ Methyldopa group } & \multicolumn{2}{|c|}{ Labetalol group } & \multirow{2}{*}{ P value } \\
\hline & Mean & SD & Mean & SD & \\
\hline SBP baseline & 152.11 & 7.25 & 152.30 & 6.76 & 0.820 \\
\hline SBP $48 \mathrm{~h}$ & 124.64 & 9.37 & 119.27 & 8.63 & $<0.001$ \\
\hline SBP 1 week & 119.55 & 8.61 & 115.26 & 8.64 & $<0.001$ \\
\hline SBP 3 weeks & 118.64 & 9.47 & 112.23 & 7.85 & $<0.001$ \\
\hline SBP 5 weeks & 115.48 & 8.92 & 112.33 & 10.63 & 0.010 \\
\hline SBP 7 weeks & 117.03 & 9.09 & 104.33 & 9.45 & $<0.001$ \\
\hline SBP 9 weeks & 117.28 & 8.66 & 105.62 & 8.48 & $<0.001$ \\
\hline SBP At delivery & 114.29 & 9.11 & 100.70 & 6.05 & $<0.001$ \\
\hline DBP baseline & 99.77 & 6.14 & 99.89 & 6.00 & 0.871 \\
\hline DBP 48 h & 89.92 & 9.26 & 85.32 & 8.85 & $<0.001$ \\
\hline DBP 1 week & 87.39 & 8.87 & 82.17 & 5.25 & $<0.001$ \\
\hline DBP 3 weeks & 86.81 & 8.00 & 80.04 & 4.49 & $<0.001$ \\
\hline DBP 5 weeks & 85.43 & 8.70 & 79.05 & 4.49 & $<0.001$ \\
\hline DBP 7 weeks & 81.11 & 5.91 & 77.58 & 4.55 & $<0.001$ \\
\hline DBP 9 weeks & 80.20 & 6.22 & 76.12 & 5.71 & $<0.001$ \\
\hline DBP At delivery & 78.60 & 5.22 & 73.55 & 7.93 & $<0.001$ \\
\hline MABP baseline & 117.04 & 4.78 & 117.19 & 4.70 & 0.802 \\
\hline MABP 48 h & 101.48 & 6.36 & 96.63 & 7.10 & $<0.001$ \\
\hline MABP 1 week & 98.10 & 6.85 & 93.19 & 4.05 & $<0.001$ \\
\hline MABP 3 weeks & 97.31 & 6.43 & 90.66 & 3.66 & $<0.001$ \\
\hline MABP 5 weeks & 95.35 & 6.37 & 90.04 & 4.79 & $<0.001$ \\
\hline MABP 7 weeks & 92.97 & 5.04 & 86.41 & 4.24 & $<0.001$ \\
\hline MABP 9 weeks & 92.44 & 4.94 & 85.86 & 4.69 & $<0.001$ \\
\hline MABP At delivery & 90.38 & 4.64 & 82.51 & 5.49 & $<0.001$ \\
\hline
\end{tabular}

Table 1: Shows a Comparison between group 1 methyldopa and group 2 labetalol group

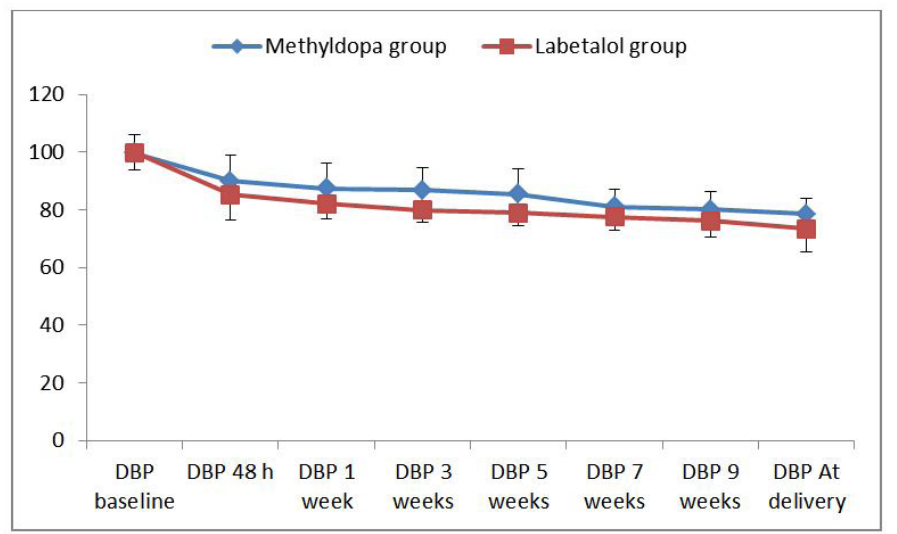

Figure 1: Shows a comparison between the 2 groups regarding Diastolic blood pressure measurements after treatment till delivery

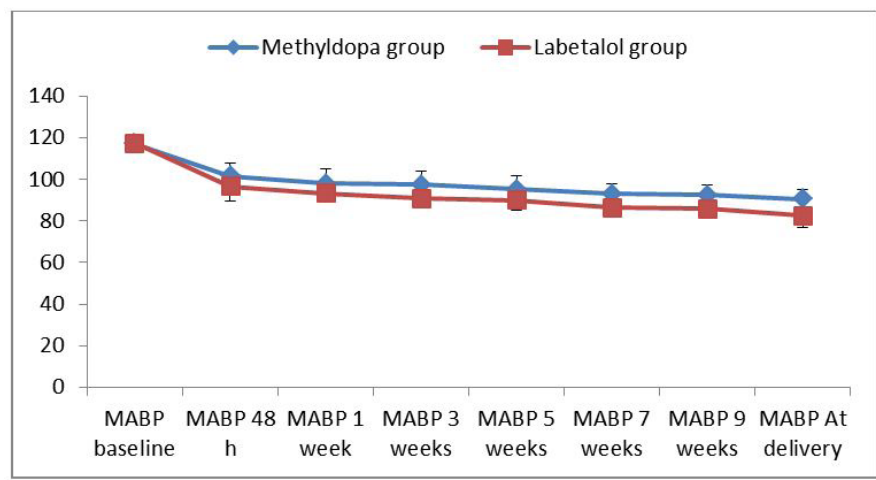

Figure 2: Shows a comparison between the 2 groups regarding mean arterial blood pressure measurements after treatment till delivery 


\begin{tabular}{|c|c|c|c|c|c|c|}
\hline & & \multicolumn{2}{|c|}{ Methyldopa group } & \multicolumn{2}{|c|}{ Labetalol group } & \multirow{2}{*}{ P value } \\
\hline & & Count & $\%$ & Count & $\%$ & \\
\hline \multirow{4}{*}{ Gravidity } & G1 & 29 & $22.0 \%$ & 37 & $28.0 \%$ & \multirow{4}{*}{0.451} \\
\hline & G2 & 42 & $31.8 \%$ & 34 & $25.8 \%$ & \\
\hline & G3 & 31 & $23.5 \%$ & 36 & $27.3 \%$ & \\
\hline & G4 & 30 & $22.7 \%$ & 25 & $18.9 \%$ & \\
\hline \multirow{4}{*}{ Parity } & P0 & 29 & $22.0 \%$ & 38 & $28.8 \%$ & \multirow{4}{*}{0.263} \\
\hline & $\mathrm{P} 1$ & 49 & $37.1 \%$ & 40 & $30.3 \%$ & \\
\hline & $\mathrm{P} 2$ & 28 & $21.2 \%$ & 35 & $26.5 \%$ & \\
\hline & P3 & 26 & $19.7 \%$ & 19 & $14.4 \%$ & \\
\hline \multirow{4}{*}{ Number of abortions } & nil & 124 & $93.9 \%$ & 123 & $93.2 \%$ & \multirow{4}{*}{1} \\
\hline & one & 5 & $3.8 \%$ & 5 & $3.8 \%$ & \\
\hline & two & 3 & $2.3 \%$ & 3 & $2.3 \%$ & \\
\hline & three & 0 & $.0 \%$ & 1 & $.8 \%$ & \\
\hline \multirow{2}{*}{ Proteinuria at delivery } & yes & 8 & $6.1 \%$ & 1 & $.8 \%$ & \multirow{2}{*}{0.036} \\
\hline & no & 124 & $93.9 \%$ & 131 & $99.2 \%$ & \\
\hline
\end{tabular}

Table 2: Comparison between the labetalol and methyldopa groups regarding age, parity, number of abortions and proteinuria

\begin{tabular}{|c|c|c|c|}
\hline \multirow{2}{*}{} & \multicolumn{2}{|c|}{ Methyldopa group } & \multirow{2}{*}{ P value } \\
\cline { 2 - 3 } & Mean & SD & \\
\hline SBP baseline & 152.11 & 7.25 & -- \\
\hline SBP 48 h & 124.64 & 9.37 & $<0.001$ \\
\hline SBP 1 week & 119.55 & 8.61 & $<0.001$ \\
\hline SBP 3 weeks & 118.64 & 9.47 & $<0.001$ \\
\hline SBP 5 weeks & 115.48 & 8.92 & $<0.001$ \\
\hline SBP 7 weeks & 117.03 & 9.09 & $<0.001$ \\
\hline SBP 9 weeks & 117.28 & 8.66 & $<0.001$ \\
\hline SBP At delivery & 114.29 & 9.11 & $<0.001$ \\
\hline
\end{tabular}

Table 3: Comparison between systolic blood pressure measurements starting before treatment (baseline) overtime till delivery in methyldopa group

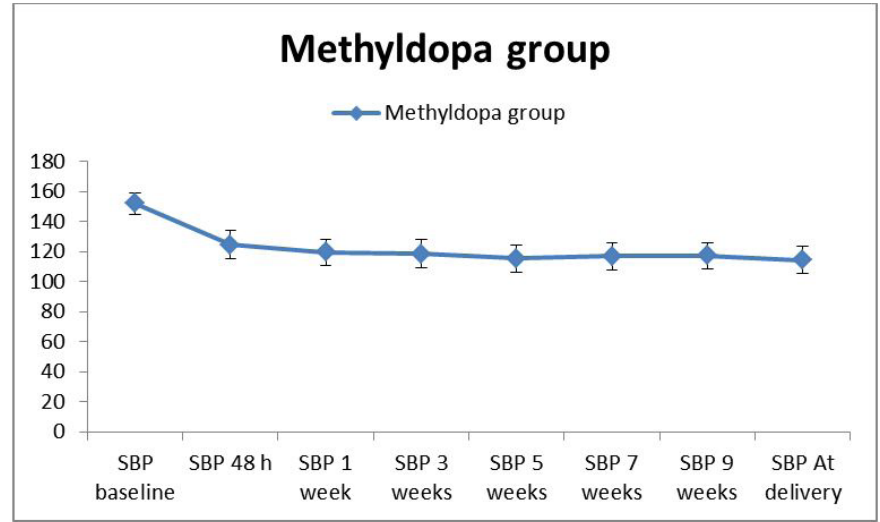

Figure 3: Comparison between systolic blood pressure measurements starting before treatment (baseline) overtime till delivery in methyldopa group

\begin{tabular}{|c|c|c|c|}
\hline \multirow{2}{*}{} & \multicolumn{2}{|c|}{ Labetalol group } & \multirow{2}{*}{ P value } \\
\cline { 2 - 3 } & Mean & SD & \\
\hline SBP baseline & 152.30 & 6.76 & -- \\
\hline SBP 48 h & 119.27 & 8.63 & $<0.001$ \\
\hline SBP 1 week & 115.26 & 8.64 & $<0.001$ \\
\hline SBP 3 weeks & 112.23 & 7.85 & $<0.001$ \\
\hline SBP 5 weeks & 112.33 & 10.63 & $<0.001$ \\
\hline SBP 7 weeks & 104.33 & 9.45 & $<0.001$ \\
\hline SBP 9 weeks & 105.62 & 8.48 & $<0.001$ \\
\hline SBP At delivery & 100.70 & 6.05 & $<0.001$ \\
\hline
\end{tabular}

Table 4: Comparison between systolic blood pressure measurements starting before treatment (baseline) overtime till delivery in labetalol group 


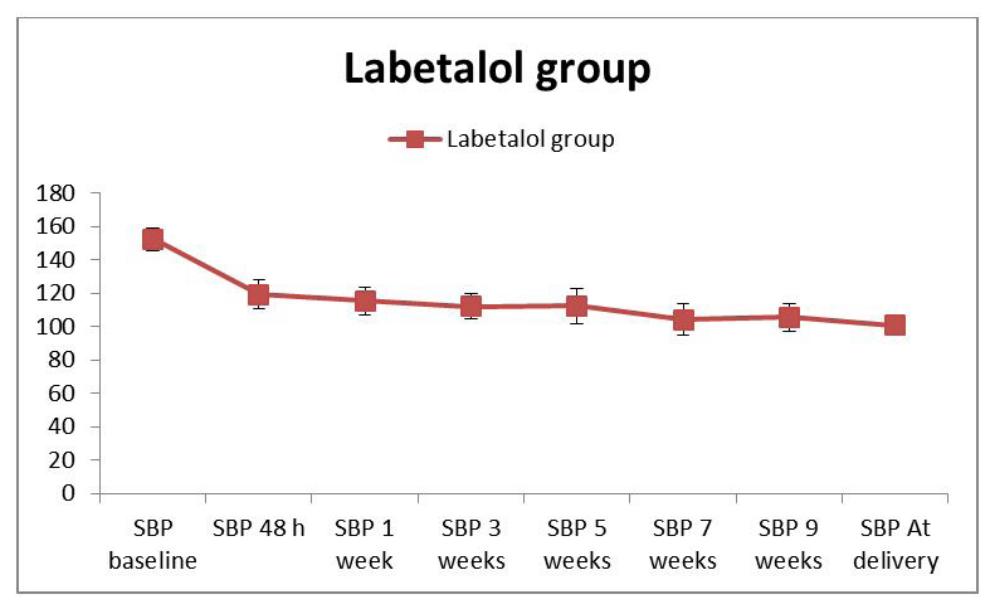

Figure 4: Comparison between systolic blood pressure measurements starting before treatment (baseline) overtime till delivery in labetalol group

\begin{tabular}{|c|c|c|c|}
\hline \multirow{2}{*}{} & \multicolumn{2}{|c|}{ Methyldopa group } & \multirow{2}{*}{ P value } \\
\cline { 2 - 3 } & Mean & SD & \\
\hline DBP baseline & 99.77 & 6.14 & -- \\
\hline DBP 48 h & 89.92 & 9.26 & $<0.001$ \\
\hline DBP 1 week & 87.39 & 8.87 & $<0.001$ \\
\hline DBP 3 weeks & 86.81 & 8.00 & $<0.001$ \\
\hline DBP 5 weeks & 85.43 & 8.70 & $<0.001$ \\
\hline DBP 7 weeks & 81.11 & 5.91 & $<0.001$ \\
\hline DBP 9 weeks & 80.20 & 6.22 & $<0.001$ \\
\hline DBP At delivery & 78.60 & 5.22 & $<0.001$ \\
\hline
\end{tabular}

Table 5: Comparison between diastolic blood pressure measurements starting before treatment (baseline) overtime till delivery in methyldopa group

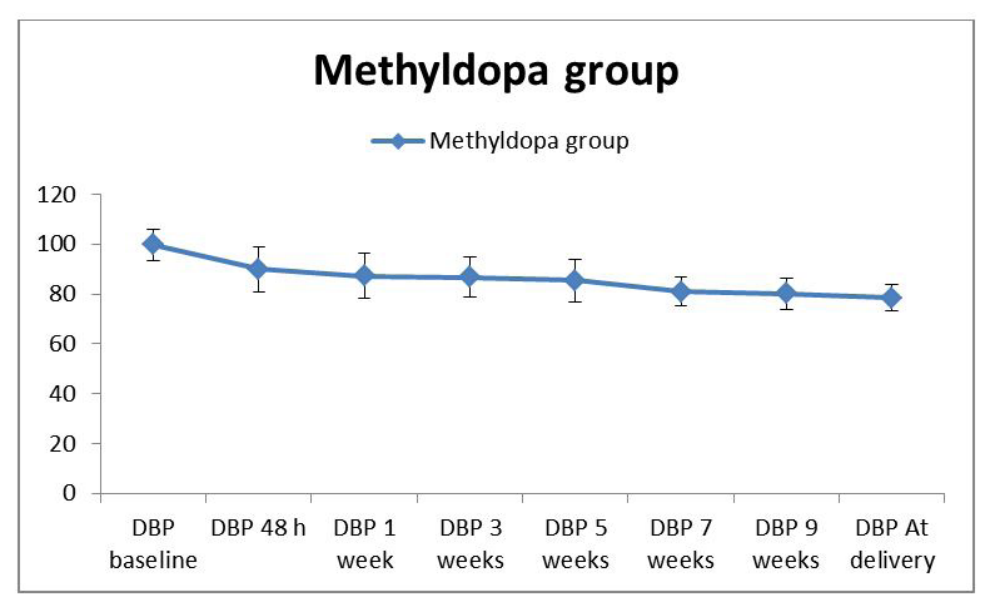

Figure 5: Comparison between diastolic blood pressure measurements starting before treatment (baseline) overtime till delivery in methyldopa group

\begin{tabular}{|c|c|c|c|}
\hline \multirow{2}{*}{} & \multicolumn{2}{|c|}{ Labetalol group } & \multirow{2}{*}{ P value } \\
\cline { 2 - 3 } & Mean & SD & \multicolumn{1}{|c|}{} \\
\hline DBP baseline & 99.89 & 6.00 & -- \\
\hline DBP 48 h & 85.32 & 8.85 & $<0.001$ \\
\hline DBP 1 week & 82.17 & 5.25 & $<0.001$ \\
\hline DBP 3 weeks & 80.04 & 4.49 & $<0.001$ \\
\hline DBP 5 weeks & 79.05 & 4.49 & $<0.001$ \\
\hline DBP 7 weeks & 77.58 & 4.55 & $<0.001$ \\
\hline DBP 9 weeks & 76.12 & 5.71 & $<0.001$ \\
\hline DBP At delivery & 73.55 & 7.93 & $<0.001$ \\
\hline
\end{tabular}

Table 6: Comparison between diastolic blood pressure measurements starting before treatment (baseline) overtime till delivery in labetalol group 


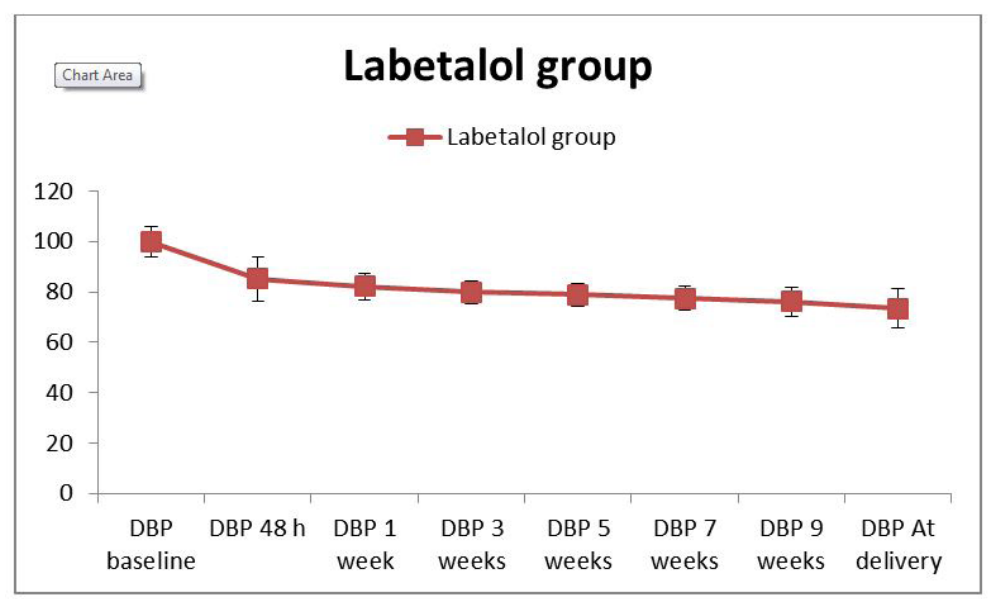

Figure 6: Comparison between diastolic blood pressure measurements starting before treatment (baseline) overtime till delivery in labetalol group

\begin{tabular}{|c|c|c|c|}
\hline \multirow{2}{*}{} & \multicolumn{2}{|c|}{ Methyldopa group } & \multirow{2}{*}{ P value } \\
\cline { 2 - 3 } & Mean & SD & \\
\hline MABP baseline & 117.04 & 4.78 & -- \\
\hline MABP 48 h & 101.48 & 6.36 & $<0.001$ \\
\hline MABP 1 week & 98.10 & 6.85 & $<0.001$ \\
\hline MABP 3 weeks & 97.31 & 6.43 & $<0.001$ \\
\hline MABP 5 weeks & 95.35 & 6.37 & $<0.001$ \\
\hline MABP 7 weeks & 92.97 & 5.04 & $<0.001$ \\
\hline MABP 9 weeks & 92.44 & 4.94 & $<0.001$ \\
\hline MABP At delivery & 90.38 & 4.64 & $<0.001$ \\
\hline
\end{tabular}

Table 7: Comparison between mean arterial blood pressure measurements starting before treatment (baseline) overtime till delivery in methyldopa group

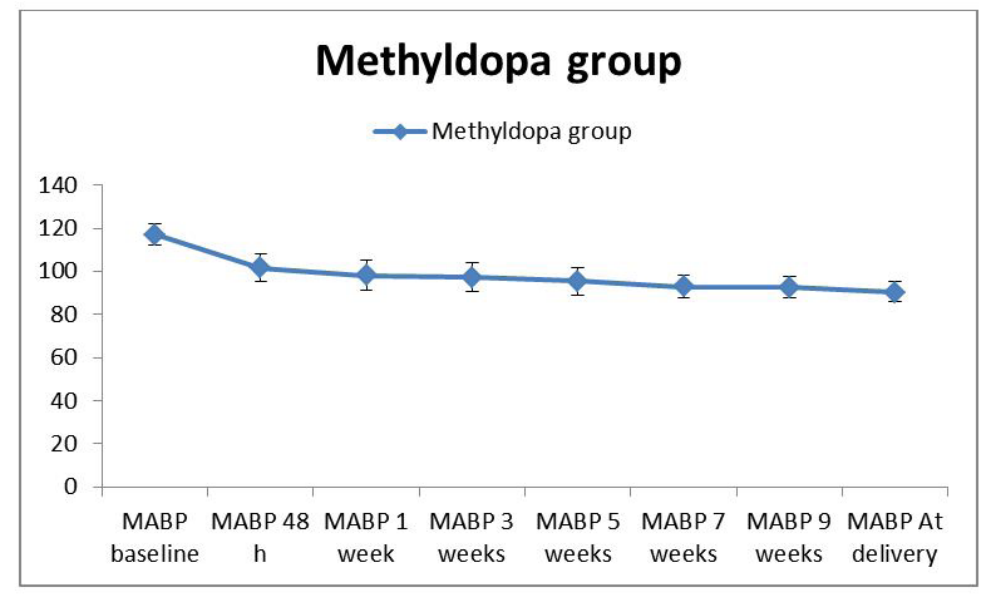

Figure 7: Comparison between mean blood pressure measurements starting before treatment (baseline) overtime till delivery in methyldopa group

\begin{tabular}{|c|c|c|c|}
\hline \multirow{2}{*}{} & \multicolumn{2}{|c|}{ Labetalol group } & \multirow{2}{*}{ P value } \\
\cline { 2 - 3 } & Mean & SD & \multirow{2}{*}{} \\
\hline MABP baseline & 117.19 & 4.70 & -- \\
\hline MABP 48 h & 96.63 & 7.10 & $<0.001$ \\
\hline MABP 1 week & 93.19 & 4.05 & $<0.001$ \\
\hline MABP 3 weeks & 90.66 & 3.66 & $<0.001$ \\
\hline MABP 5 weeks & 90.04 & 4.79 & $<0.001$ \\
\hline MABP 7 weeks & 86.41 & 4.24 & $<0.001$ \\
\hline MABP 9 weeks & 85.86 & 4.69 & $<0.001$ \\
\hline MABP At delivery & 82.51 & 5.49 & $<0.001$ \\
\hline
\end{tabular}

Table 8: Comparison between mean arterial blood pressure measurements starting before treatment (baseline) overtime till delivery in labetalol group 


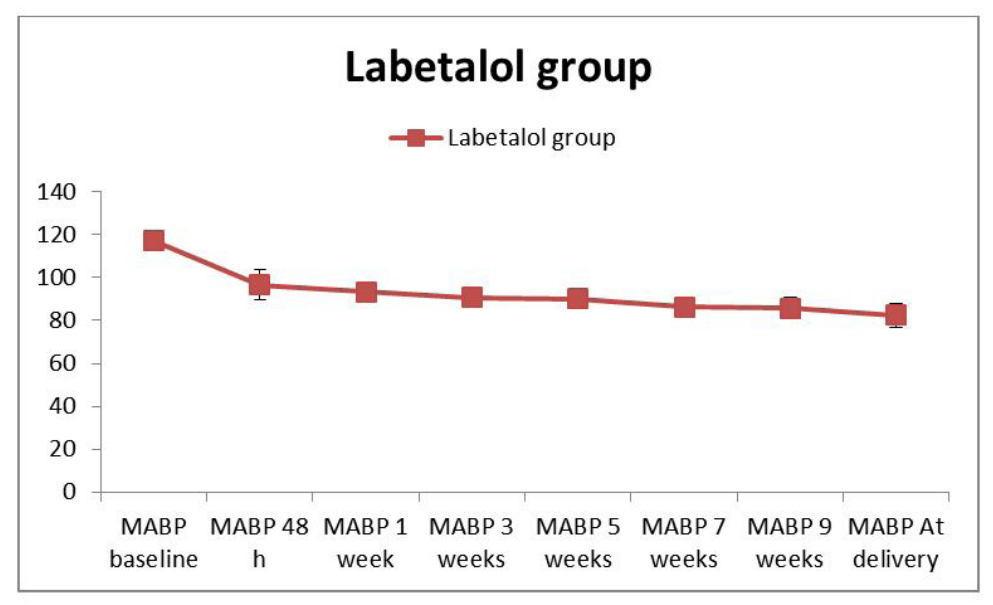

Figure 8: Comparison between mean arterial blood pressure measurements starting before treatment (baseline) overtime till delivery in labetalol group

\section{Discussion}

$\mathrm{PIH}$ is a major cause of fetal and maternal morbidity and mortality and protection from its development is not always possible as its pathology is not completely predictable.Various medications are used in controlling hypertensive abnormalities during pregnancy [13].

In a Study made by Verma et al. denoted that adverse outcome was evidently less in the labetalol treated pregnant women compared to the methyldopa group [10].

In a study made by El-Qarmalawi et al. patients received methyldopa experienced side-effects as drowsiness (22.2\%), headache (14.8\%), nasal congestion (7.4\%), and postural hypotension (5.6\%). While 96 pregnant ladies in labetalol group complained from dyspnea, no other side-effects were documented [14].

In the present study, there is a decrease in the systolic blood pressure readings starting from a baseline which was the blood pressure before intake of the antihypertensive treatment and the measurements after 48 hours, 1, 3, 5, 7, 9 weeks after drug intake and at time of delivery in the methyldopa and labetalol group.

Verma et al. made a study and mentioned the age distribution which showed maximum patients between 19-24 years in both groups (64.44\% in methyldopa group and $57.77 \%$ in labetalol group) and there was no significant difference in age distribution in both groups [13].

In the present study, there was a decrease in the diastolic blood pressure readings starting from a baseline which was the blood pressure before intake of the antihypertensive treatment and the measurements after 48 hours, 1, 3, 5, 7, 9 weeks after drug intake and at time of delivery in the methyldopa and labetalol group.

Most common age group is in contrast to the data obtained from a large database study indicate a linear relationship between age and incidence of PIH [15].

In the present study, there was a decrease in the mean arterial blood pressure readings starting from a baseline which was the blood pressure before intake of the antihypertensive treatment and the measurements after 48 hours, 1, 3, 5, 7, 9 weeks after drug intake and at time of delivery in the methyldopa and labetalol group.

In a study made by Dharwadkar MN et al. about 32.5 percent of the pregnant ladies in Methyldopa group and $37.5 \%$ in Labetalol group were primigravidae. The rest of the patients were multigravidae. However the percentage of primigravidae is greater in most other studies where the prevalence of primigravidae was $50 \%$ or above $[16,17,22]$.

In the present study, our results show a statistically significant difference in control of blood pressure with values of systolic, diastolic and mean arterial blood pressure measurements are less in labetalol group than in methyldopa group after 48 hours, 1, 3, $5,7,9$ weeks post drug therapy and at time of delivery with $\mathrm{P}$ value $<0.001$ indicating a better control of blood pressure.

Labetalol is an effective antihypertensive drug which decreases both systolic and diastolic BP in pregnancy induced hypertension. About 55\% of the methyldopa group received nifedepine and phenobarbitonewhere as only $22.5 \%$ of labetalol group received injections of labetalol and phenobarbitone showed that methyl dopa requires additional drugs to decrease BP than labetalol [18].

In a previous study demonstrated that labetalol is an efficient drug in decreasing blood pressure of the patients and then maintain optimal BP levels [22]. 
Similarly, Cruickshank et al. study revealed that Labetalol controlled the blood pressure in 45 of the 51 treated women (88\%) within 24 hrs $[19,20]$.

Marked decrease of both systolic and diastolic pressure within 24 and 48 hours from the onset of using methyldopa was observed by Hans and Kopelman [21].

Also in the present study, there was a considerable difference in pregnant women who developed proteinuria after the same dose of treatment by both drugs, as in the group of women received methyldopa there was 8 ladies developed proteinuria checked at time of delivery while in labetalol there was only one lady who had proteinuria at time of delivery with $\mathrm{P}$ value of 0.036 ,indicate a statistically significant value that denotes better control of arterial blood pressure and prevention of progression to preeclampsia with labetalol than with methyldopa treatment.

Future researches can be made on a larger number of pregnant women to compare various drugs used in treatment of hypertension.

\section{Conclusion}

The present study confirms that labetalol is an effective and safe drug for use and is more rapid in achieving adequate control of blood pressure in PIH. With a low chance of fetomaternal side-effects and this makes it appropriate to be used in PIH. Labetalol gives good control of blood pressure than methyldopa and decreases the liability for proteinuria and for progression to preeclampsia.

Labetalol has the advantage of decreasing peripheral vascular resistance with no decrease in cardiac output of the mother and heart rate and so better uteroplacental perfusion than methyldopa.

\section{Acknowledgement}

Special thanks to residents of obstetrics and Gynecology in Ain Shams Maternity Hospital, Kasralainy Obstetrics and Gynecology hospital and in National Research Centre, Egypt for their cooperation in this research.

\section{References}

1. Dasgupta S, Nasim S, Khanna M (2008) Hypertensive disorders of pregnancy In: Practical guide to high-risk pregnancy and delivery-a South Asian perspective $\left(3^{\text {rd }}\right.$ Edn) Elsevier Publication, New Delhi, India.

2. Shah MR (2007) Clinical examination of hypertension in pregnancy. In: Hypertensive disorders in pregnancy ( $1^{\text {st }}$ Edn) Jaypee Brothers Medical Publishers, India.

3. Duley L, Henderson-Smart DJ, Meher S (2006) Drugs for treatment of very high blood pressure during pregnancy. Cochrane Database Syst Rev: CD001449.

4. Steegers EA, von Dadelszen P, Duvekot JJ, Pijnenborg R (2010) Preeclampsia. Lancet 376: 631-44.

5.Hernández-Diaz S, Van Marter LJ, Werler MM, Louik C, Mitchell AA (2007) Risk factors for persistent pulmonary hypertension of the newborn. Pediatrics 120: e272-82.

6.Saftlas AF, Logsden-Sackett N, Wang W, Woolson R, Bracken MB (2004) Work, leisure-time physical activity, and risk of preeclampsia and gestational hypertension. Am J Epidemiol 160: 758-65.

7. Skjaerven R, Vatten LJ, Wilcox AJ, Rønning T, Irgens LM, et al. (2005) Recurrence of pre-eclampsia across generations: exploring fetal and maternal genetic components in a population based cohort. BMJ 331: 877.

8. Abalos E, Duley L, Steyn D, Henderson-Smart D (2007) Antihypertensive drug therapy for mild to moderate hypertension during pregnancy. Cochrane Database Syst 24: CD002252.

9. Giannubilo SR, Bezzeccheri V, Cecchi S, Landi B, Battistoni GI, et al. (2012) Nifedipine versus labetalol in the treatment of hypertensive disorders of pregnancy. Arch Gynecol Obstet 286: 637-42.

10. el-Qarmalawi AM, Morsy AH, al-Fadly A, Obeid A, Hashem M (1995) Labetalol vs. methyldopa in the treatment of pregnancy-induced hypertension. Int J Gynaecol Obstet 49: 125-30.

11. Khedun SM, Moodley J, Naicker T, Maharaj B (1997) Drug management of hypertensive disorders of pregnancy. Pharmacol Ther 74: 221-58.

12. Lamming GD, Symonds EB (1979) Use of labetalol and methyldopa in pregnancy-induced hypertension. Br J Clin Pharmacol 8: 217S-22S.

13. Verma R, Lahon K, Tonpay SD, Kale VJ, Jain DK (2012) A comparative randomized controlled parallel group study of efficacy and tolerability of labetalol versus methyldopa in the treatment of new onset hypertension during pregnancy. Pharmacology 2: 23-31.

14. Wallis AB, Saftlas AF, Hsia J, Atrash HK (2008) Secular trends in the rates of preeclampsia, eclampsia, and gestational hypertension, United States, 1987-2004. Am J Hypertens 21: 521-6.

15. Guzick DS, Klein VR, Tyson JE, Lasky RE, Gant NF, et al. (1987) Risk factors for the occurrence of pregnancy induced hypertension. Informa healthcareHypertension in pregnancy 6: 281-97.

16. Redman CW (1976) Fetal outcome in trial of antihypertensive treatment in pregnancy. Lancet 2: 753-6.

17. Plouin PF, Breart G, Maillard F, Papiernik E, Relier JP (1988) Comparison of antihypertensive efficacy and perinatal safety of labetalol and methyldopa in the treatment of hypertension in pregnancy: a randomized controlled trial. Br J Obstet Gynaecol 95: 868-76.

18. Cruickshank DJ, Robertson AA, Campbell DM, MacGillivray I (1992) Does labetalol influence the development of proteinuria in pregnancy hypertension?A randomised controlled study. Eur J Obstet Gynecol Reprod Biol 45: 47-51.

19. Lardoux H, Gerard J, Blazquez G, Chouty F, Flouvat B (1983) Hypertension in pregnancy: evaluation of two beta blockers atenolol and labetalol. Eur Heart J Suppl G: 35-40.

20. Michael CA (1979) Use of labetalol in the treatment of severe hypertension during pregnancy. Br J Clin Pharmacol 8: 211S-5S.

21. Hans SF, Kopelman H (1964) methyldopa in treatment of severe toxaemia of pregnancy. Br Med J 1: 736-9.

22. Dharwadkar MN, Kanakamma MK, Dharwadkar SN, Rajagopal K, Gopakumar C, et al. (2014) Study of Methyl Dopa Versus Labetalol in Management of Preeclampsia and Gestational Hypertension. Gynecol Obstet 4: 10.4172/2161-0932.1000242. 


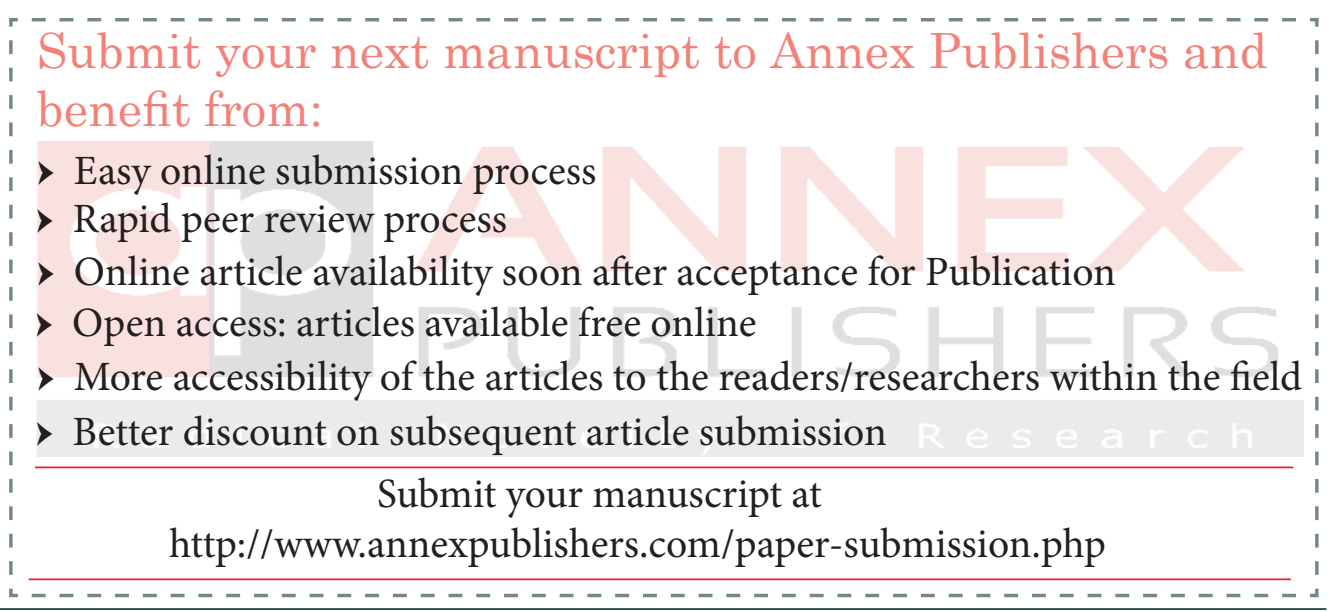

